This item was submitted to Loughborough's Research Repository by the author.

Items in Figshare are protected by copyright, with all rights reserved, unless otherwise indicated.

\title{
Solubilization of phenols by multimolecular aggregates formed by low molecular weight hyperbranched polyglycidol
}

\section{PLEASE CITE THE PUBLISHED VERSION}

http://dx.doi.org/10.1016/j.colsurfa.2017.02.032

\section{PUBLISHER}

(C) Elsevier

VERSION

AM (Accepted Manuscript)

\section{PUBLISHER STATEMENT}

This work is made available according to the conditions of the Creative Commons Attribution-NonCommercialNoDerivatives 4.0 International (CC BY-NC-ND 4.0) licence. Full details of this licence are available at: https://creativecommons.org/licenses/by-nc-nd/4.0/

\section{LICENCE}

CC BY-NC-ND 4.0

\section{REPOSITORY RECORD}

Olea, Andres F., Betsabe Acevedo, Luis Ossandon, and David R. Worrall. 2019. "Solubilization of Phenols by Multimolecular Aggregates Formed by Low Molecular Weight Hyperbranched Polyglycidol". figshare. https://hdl.handle.net/2134/24523. 


\title{
Solubilization of phenols by multimolecular aggregates formed by low molecular weight hyperbranched polyglycidol
}

\author{
Andres F. Olea ${ }^{1}$, Betsabe Acevedo ${ }^{2}$, Luis Ossandon ${ }^{2}$, David Worrall ${ }^{3}$ \\ ${ }^{1}$ Instituto de Ciencias Químicas Aplicadas, Universidad Autonoma de Chile, Santiago, \\ Chile \\ ${ }^{2}$ Universidad Andrés Bello, Viña del Mar, Chile \\ ${ }^{3}$ Department of Chemistry, Loughborough University, Leicestershire LE11 3TU, UK
}

\begin{abstract}
Hyperbranched polymers have been proposed as potential carriers or host compartments for controlled drug delivery. In this work the solubilization of alkylphenols into aggregates formed by hyperbranched polyglycidol HPG and its ester derivative has been studied. $\mathrm{HPG}_{17}$ was synthesized by ring-opening polymerization of glycidol, and then the ester $\mathrm{HPG}_{4}-\mathrm{RBr}_{13}$ has been obtained by reaction of $\mathrm{hPG}_{17}$ with 2-bromo isobutyryl bromide. The critical aggregate concentration CAC and micropolarity of aggregates were determined by using pyrene as fluorescence probe. CAC values obtained are $2.5 \mathrm{mM}$ and $0.25 \mathrm{mM}$, for $\mathrm{HPG}_{17}$ and $\mathrm{HPG}_{4}-\mathrm{RBr}_{13}$, respectively. Our results indicate that the hydrophobic effect is larger for $\mathrm{HPG}_{4}-\mathrm{RBr}_{13}$, and that their aggregates are more hydrophobic, than for $\mathrm{HPG}_{17}$. In addition, their sizes and sizes distribution were determined by DLS.

The partition of phenols between the micellar and aqueous phase was studied by using the pseudo-phase model, and the results show that the partition coefficients increases with increasing length of the side alkyl chain, and are larger for $\mathrm{HPG}_{4}-\mathrm{RBr}_{13}$ micelles than for $\mathrm{HPG}_{17}$ micelles.
\end{abstract}




\section{Introduction}

Hyperbranched polymers (HBP) have received much attention due to their relative ease of synthesis and narrow dispersity [1-4]. The potential use of HBPs in many applications is related to their unique properties, i.e. HBPs are branched polymers with dendritic globular structure and a large number of terminal functional groups. The branching structure of these polymers determine many of their properties, such as viscosity, glass transition temperature, and crystallization behavior [5]. These structures with a hydrophobic core and hydrophilic shell linked by covalent bonds resemble a micellar architecture. As each macromolecule constitutes a single "micelle", there is no critical micelle concentration (CMC), and these systems are referred as unimolecular micelles. Thus, bioactive molecules can be incorporated into their compact and globular structures by simple physical entrapment or by chemical attachment to the terminal functional groups. In this way, a number of active molecules can be conjugated to each unimolecular micelle reaching a high local concentration. These properties have prompted an increasing number of investigations to develop novel HBP for different kinds of applications [6-10].

However, recently it has been shown that amphiphilic HBPs can self-assemble into a diversity of supramolecular structures [11-14]. This is an unexpected and interesting result as it is in contrast to the view of HBP as unimolecular entities. The number of morphologies and structures of assemble HBPs and their unique properties have converted them in promising systems for biomedical applications [15-17]. Self-assembling HBPs are formed by hydrophobic (hydrophilic) dendritic core and hydrophilic (hydrophobic) arms. A multimolecular aggregate mechanism driven by intermolecular interaction between hydrophobic arms has been proposed to explain the formation of large aggregates over 100 $\mathrm{nm}[18,19]$. 
Hyperbranched polyglycidol HPG is biocompatible polyether with a hydrophilic core and a number of terminal hydroxyl groups. Conjugation of hydrophobic molecules to the terminal groups changes the arms' hydrophobicity and large multimolecular aggregates (MMA) with different shapes can be formed. Formation of large aggregates at a critical aggregate concentration CAC has been reported for HPG in which the terminal hydroxyl groups have been modified by long alkyl chains [20], adamantyl group [21], or amphiphilic chains forming core-multishell structures [19,22,23]. Despite in many applications the encapsulation ability of MMA is a determinant factor; to the best of our knowledge the thermodynamic parameters that control this process have not been studied.

For many applications the incorporation of guest molecules into MMA is a determinant factor; however, to the best of our knowledge the thermodynamic parameters that control this process have not been studied. In this work, the formation of MMA by a low molecular weight HPG and its ester derivative has been studied. The CAC has been determined by fluorescence probing methods, and the distribution constants between the aqueous phase and the pseudo-micellar phase have been measured for a series of alkylphenols. These molecules have been used as model compounds in studies of solubilization of organic molecules into micelles formed by normal surfactants and amphiphilic polymers [24-26]. The thermodynamic parameters obtained are the distribution constants and standard free energy of transfer. Thus, our results can be compared to those obtained with other micellar systems in order to understand the solubilization process and to assess the ability of HPG aggregates to solubilize hydrophobic molecules.

\section{Materials and Methods}

\subsection{Materials}


Glycidol (Aldrich), 1,1,1-tris(hydroximethyl)propane TMP (Fluka), 2-bromoisobutyryl bromide (Merck), PMDETA (Aldrich) and p-alkylphenols (Aldrich) were used as received. Polymerizations were carried out following the methodology reported in the literature $[1,27,28]$. A typical polymerization reaction of glycidol was conducted as follows. Initially TMP was added with mechanical agitation under argon atmosphere into a two-neck roundbottom flask, followed by potassium methylate solution in methanol (20\%). The mixture was stirred for several minutes, after which excess methanol was removed by distillation. The temperature was raised to $95{ }^{\circ} \mathrm{C}$ and $25 \mathrm{~mL}$ of glycidol slowly added over a period of $12 \mathrm{~h}$ using a syringe pump. The product was dissolved in methanol and neutralized by passing through a cation-exchange column. The polymer was precipitated from methanol solution using excess acetone and dried at $80^{\circ} \mathrm{C}$ in vacuum.

Esterification of the hydroxyl groups of HPG was accomplished in pyridine as solvent [28]. The acyl bromide, 2-bromoisobutyryl bromide, was added dropwise at $50{ }^{\circ} \mathrm{C}$. The initial yellow color disappeared and pyridinium bromide precipitated. Pyridine was removed by azeotropic distillation with toluene. The residue was dried with $\mathrm{MgSO}_{4}$ and a pale yellow viscous liquid was obtained.

${ }^{1} \mathrm{H}$ and ${ }^{13} \mathrm{C}$ NMR spectra were recorded in $\mathrm{CD}_{3} \mathrm{OD}$ on a Bruker Avance 400 spectrometer operating at 400.1 and 100.6 MHz, respectively (Figures 1-2, Supplementary Material). MALDI-TOF mass spectra were performed with a Microflex mass spectrometer (Bruker Daltonics).

\subsection{Dynamic light scattering}

The size and size distributions of polymeric micelles were determined by dynamic light scattering (DLS). Aqueous solutions of polymers $(1 \mathrm{mg} / \mathrm{mL})$ in the absence and presence of p-alkylphenols $(10 \mathrm{mM})$ were prepared with deionized water from an ultrapure water 
system (EasyPure II, Barnstead), filtered, and thermostatted at $25^{\circ} \mathrm{C}$ for $10 \mathrm{~m}$. DLS measurements were performed using a Zetasizer Nano ZS (Malvern Instruments, Malvern, UK) at a scattering angle of $175^{\circ}$ to the incident beam provided by a He-Ne laser (633 nm, $4 \mathrm{~mW}$ ). The resulting data were analyzed using the manufacturer's software (DTS v. 4.2, Malvern Instruments Ltd., Malvern, UK). The hydrodynamic diameter and dispersity index (PDI) are expressed as the average of at least three measurements.

\subsection{Fluorescence probing}

Samples for fluorescence measurements were prepared by adding a concentrated solution of pyrene in acetonitrile to aqueous solutions of polymers. Steady-state fluorescence spectra of pyrene were recorded utilizing a Horiba Jobin Yvon Fluoromax 4 fluorometer by exciting at $337 \mathrm{~nm}$. All emission spectra were corrected for detector response using a correction curve supplied by the instrument manufacturer. The ratio $I_{1} / I_{3}$ corresponds to the ratio of intensities of peak one $(\lambda=372 \mathrm{~nm})$ to peak three $(\lambda=384 \mathrm{~nm})$, whereas the ratio $\mathrm{I}_{\mathrm{M}} / \mathrm{I}_{\mathrm{E}}$ corresponds to the ratio of intensities of the monomer band to the excimer band $(\lambda=450$ $\mathrm{nm})$.

\subsection{Measurement of distribution coefficients}

In the pseudo-phase model the solubilization process is represented by the equilibrium

$$
\mathrm{S}_{\mathrm{W}}+\mathrm{P}_{\mathrm{M}} \rightleftarrows \mathrm{S}_{\mathrm{M}}
$$

For which the equilibrium constant Ks is given by

$$
K_{S}=\frac{[S]_{M}}{[S]_{W}[P]_{M}}
$$

where $[S]_{W}$ and $[S]_{M}$ denote molar concentration of substrate in aqueous and in the

polymeric pseudo-phase, respectively; $[\mathrm{P}]_{\mathrm{M}}$ is the concentration of polymer chains forming 
the hydrophobic aggregates. On a mole fraction basis the partition coefficient can be expressed by

$$
K_{X}=\frac{X_{M}}{X_{W}}
$$

where $\mathrm{X}_{\mathrm{M}}$ and $\mathrm{X}_{\mathrm{W}}$ are the mole fraction of substrate in the micellar and aqueous phases, respectively. In diluted solutions, both quantities are related by

$$
\mathrm{K}_{\mathrm{X}}=55.5 \mathrm{~K}_{\mathrm{S}}
$$

The distribution coefficients $\left(\mathrm{K}_{\mathrm{S}}\right)$ were obtained by ultrafiltration using an Amicon 202 cell with a PM5 membrane, which has a MW cut-off of 5,000. Aqueous solutions of PG and PG-Br (10mM and $0.28 \mathrm{mM}$, respectively) containing different concentrations of palkylphenols were filtered, and the absorbances of the filtrate were measured at $275 \mathrm{~nm}$. The molar concentrations of phenols were obtained from a calibration curve. The values of $\mathrm{K}_{\mathrm{S}}$ were obtained from the initial slope of a plot of $\left[\mathrm{S}_{\mathrm{M}}\right]$ against $\left[\mathrm{S}_{\mathrm{W}}\right]$.

\section{Results and Discussion}

\subsection{Synthesis of hyperbranched polymers}

Hyperbranched polyglycidol was obtained by anionic ring opening polymerization of glycidol and using a multibranched initiator. Partially deprotonated TMP was used as the initiator and the anionic polymerization was carried out with slow monomer addition. The polymer was characterized by FT-IR, ${ }^{1} \mathrm{H}$ NMR, ${ }^{13} \mathrm{C}$ NMR and MALDI-TOF. The degree of branching (DB) was determined by measuring the intensity of ${ }^{13} \mathrm{C}$ NMR signals, according to the procedure described by Sunder et al. [1] The DB value calculated for HPG is 0.41 that is slightly lower than the value expected for this polymerization. HPG was

subsequently esterified with 2-bromoisobutyril bromide to get a more hydrophobic 
polymer, HPG-RBr (see Scheme 1). The fraction of $-\mathrm{OH}$ groups that were esterified was determined by FT-IR (Figure 3, Supplementary Material). The conversion degree is 78\% which is similar to values previously reported [28].

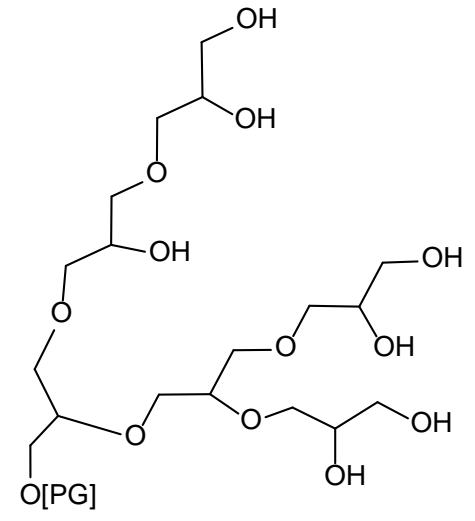

HPG

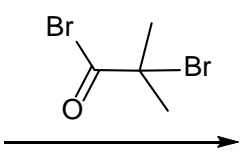

HPG-RBr

SCHEME 1. Esterification of HPG with 2-bromoisobutyryl bromide

The molecular weights of HPG and HPG-RBr were determined by MALDI-TOF mass spectrometry and the results are given in table 1.

Table 1. Molecular weights of HPG and HPG-Br determined by MALDI-TOF

\begin{tabular}{|l|c|l|l|}
\hline Polymer & Mn & Mw & Mw/Mn \\
\hline HPG $_{17}$ & 1260 & 1500 & 1.19 \\
\hline $\mathrm{HPG}_{4}-\mathrm{RBr}_{13}$ & 3210 & 3640 & 1.13 \\
\hline
\end{tabular}

The results indicate that HPG was obtained with a very narrow dispersity and that esterification with 2-bromoisobutyril bromide brings about an increase of the molecular weight with no change in dispersity. In addition, by comparing the values of Mn for HPG 
and HPG-RBr, and considering that for each $-\mathrm{OH}$ group that reacts the molecular weight increases by $150 \mathrm{~g} / \mathrm{mol}$, it can be concluded that 13 out of $17-\mathrm{OH}$ groups were esterified. This corresponds to $78 \%$ of conversion and it is consistent with the degree of conversion determined by FT-IR.

Therefore, two hyperbranched polymers with different numbers of -OH groups have been synthesized, i.e. $\mathrm{HPG}_{17}$ and $\mathrm{HPG}_{4}-\mathrm{RBr}_{13}$.

\subsection{Characterization of polymer aggregates}

Hyperbranched polyglycidol is a highly flexible polymer that in aqueous solution adopts a globular form with a core-shell structure. Thus, it is expected that $\mathrm{HPG}_{17}$ and $\mathrm{HPG}_{4}-\mathrm{RBr}_{13}$ form unimolecular micelles at low concentration, and probably multimolecular aggregates at higher polymer concentration. The aggregation of unimolecular micelles to form multimolecular aggregates has been demonstrated for hyperbranched star copolymers [18]. The formation of multimolecular aggregates can be evidenced by detection of the critical aggregate concentration (CAC), i.e. the polymer concentration at which aggregates are formed. The CAC and micro polarity of the aggregates formed by $\mathrm{HPG}_{17}$ and $\mathrm{HPG}_{4}-\mathrm{RBr}_{13}$ were determined by using pyrene as a fluorescent probe. It is well established that the fluorescence of pyrene changes dramatically with the polarity of the medium, and the ratio $\mathrm{I}_{1} / \mathrm{I}_{3}$ of the intensities of the bands that appear at $372 \mathrm{~nm}\left(\mathrm{I}_{1}\right)$ and $390 \mathrm{~nm}\left(\mathrm{I}_{3}\right)$ has been used to monitor conformational transitions in polyelectrolytes containing carboxylic groups in the side chain, and self-aggregation of amphiphilic copolymers [29-32]. To determine the CAC the ratio $I_{1} / I_{3}$ was measured as a function of both $\mathrm{HPG}_{17}$ and $\mathrm{HPG}_{4}-\mathrm{RBr}_{13}$ concentrations. A plot of this ratio against polymer concentration is shown in Fig. 1. 


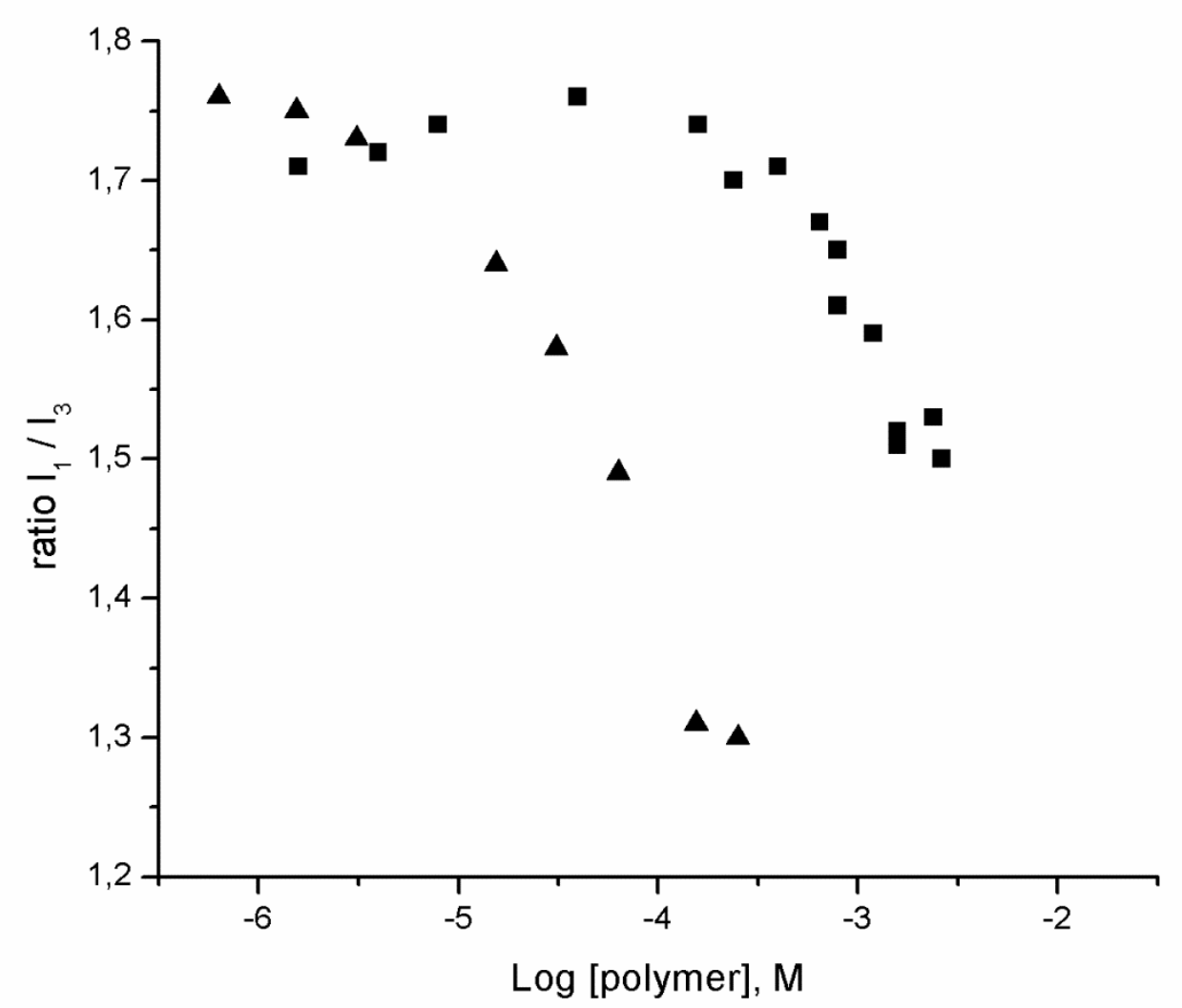

Figure 1. Plot of ratio $I_{1} / I_{3}$ against the logarithm of the polymer concentration: $\mathrm{HPG}_{17}(\mathbf{\bullet})$; $\mathrm{HPG}_{4}-\mathrm{RBr}_{13}(\mathbf{\Delta})$

At low concentrations of both polymers the values of $I_{1} / I_{3}$ are lower than the value measured in aqueous solution. These results confirm that HPG polymers form unimolecular micelles providing a microenvironment for pyrene even at the lowest concentration used. The polarity of this environment is quite similar to water due mainly to the flexibility of the dendritic polymer which allows easy entry to water molecules. This flexibility might be due to the low degree of branching and the presence of ether bonds in the dendritic structure. With increasing polymer concentration the value of $I_{1} / I_{3}$ decreases steeply, until a constant value is reached. This breaking point is associated with the critical aggregate concentration, 
whereas the limiting values of $\mathrm{I}_{1} / \mathrm{I}_{3}$ represent the polarity sensed by pyrene in the hydrophobic sites provided by polymer aggregates. CAC values obtained from Fig. 1 are $2.5 \mathrm{mM}$ and $0.25 \mathrm{mM}$ for $\mathrm{HPG}_{17}$ and $\mathrm{HPG}_{4}-\mathrm{RBr}_{13}$, respectively. These CAC are much higher than those measured for branched poly(ethylene imine) functionalized with long alkyl chains and monomethyl poly(ethylene glycol) mPEG [33]. For the latter, the CAC values are in the range $10^{-7}$ to $10^{-5} \mathrm{M}$, which suggest a high stability of the multimolecular aggregates. This effect was attributed to the interaction between long aliphatic chains [33]. The same explanation has been given for the aggregation of HPG derivatized with $\mathrm{C}_{18}$ alkyl chains and mPEG [34], even though in this case no CAC could be determined by solubilization methods because the aggregate collapse with the addition of solute molecules. Thus, the main driven force for aggregation of these HPG might be the hydrophobic interaction of ether chains or 2-bromoisobutyrate groups. In addition, the formation of hydrogen bonds could make an important contribution for aggregation of unimolecular micelles of $\mathrm{HPG}_{17}$. On the other hand, the limiting values of $\mathrm{I}_{1} / \mathrm{I}_{3}$ are 1.50 and 1.30 for $\mathrm{HPG}_{17}$ and $\mathrm{HPG}_{4}-\mathrm{RBr}_{13}$, respectively. These results indicate that $\mathrm{HPG}_{4}-\mathrm{RBr}_{13}$ multimolecular aggregates are more stable and more hydrophobic than those formed by $\mathrm{HPG}_{17}$. These effects arise from a reduced number of $-\mathrm{OH}$ groups, forming the outer corona, and the presence of 2-bromoisobutyrate groups in the hydrophobic dendritic core. It has been shown that in polymer micelles having a core-shell structure, non-polar molecules are distributed between the core and the inner corona [35,36]. The distribution of pyrene has been demonstrated by quenching of pyrene fluorescence by nitromethane, a water-soluble molecule [36]. Results indicate that pyrene located in the corona is more exposed to water, and therefore is more efficiently quenched by nitromethane relative to that localized in the core. As consequence of this preferential quenching the plots of $\mathrm{I}_{0} / \mathrm{I}$ 
against quencher concentration are not linear, as would be predicted by the Stern Volmer equation, and show a downward curvature. In Fig. 2 are presented Stern-Volmer plots for the quenching of pyrene $(1.0 \mu \mathrm{M})$ in aqueous solutions of hyperbranched polymers at concentrations above the CAC, i.e. $1.0 \times 10^{-2}$ and $2.8 \times 10^{-4} \mathrm{M}$ for $\mathrm{HPG}_{17}$ and $\mathrm{HPG}_{4}-\mathrm{RBr}_{13}$, respectively. These results indicate that pyrene is clearly distributed between two different environments, one of them being more difficult access by water soluble quenchers.

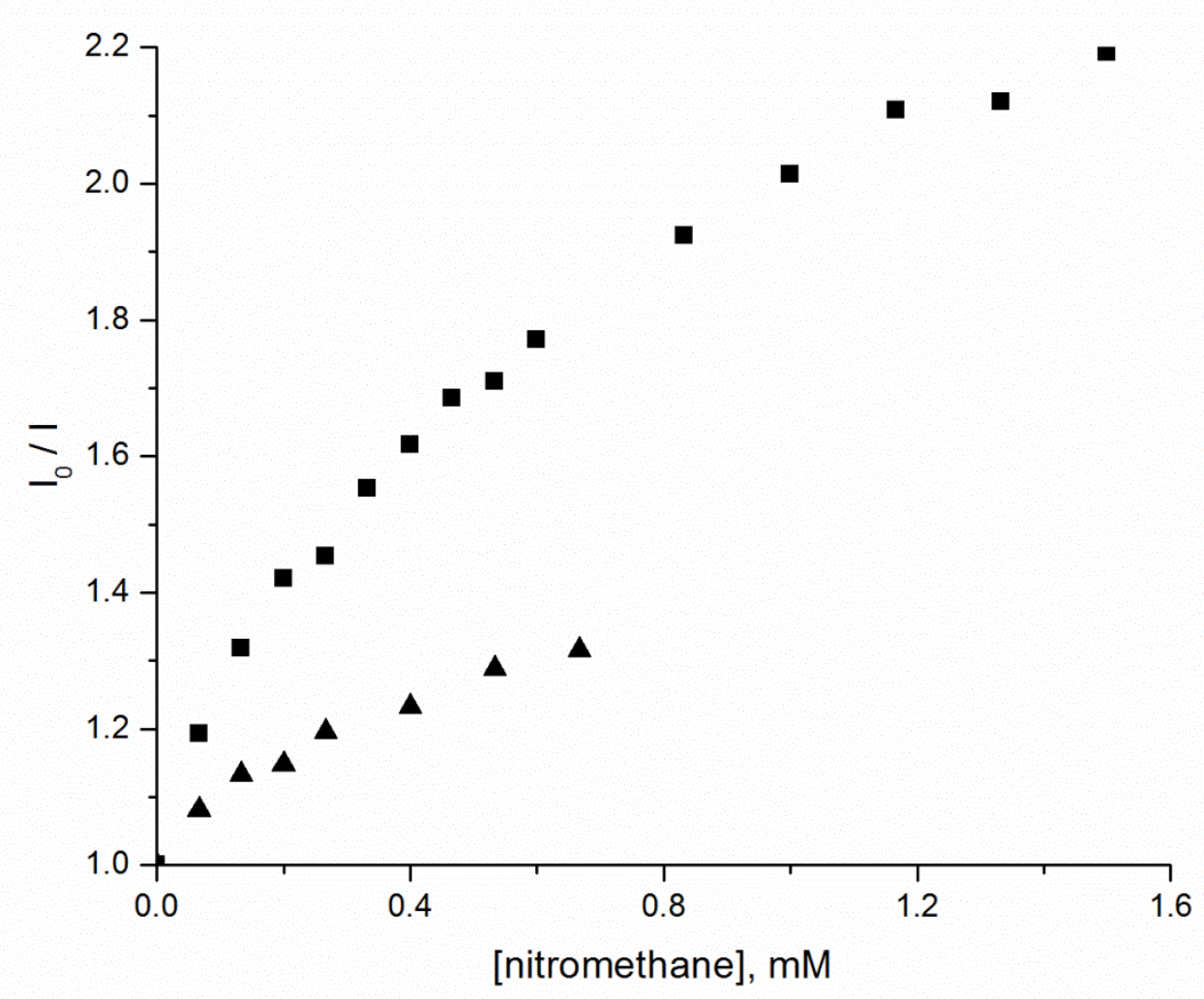

Figure 2. Quenching of pyrene fluorescence by nitromethane in aqueous solution of $\mathrm{HPG}_{17}$ (匹) and $\mathrm{HPG}_{4}-\mathrm{RBr}_{13}(\mathbf{\Delta})$. [Pyrene $]=1 \mu \mathrm{M} ;\left[\mathrm{PG}_{17}\right]=10 \mathrm{mM} ;\left[\mathrm{PG}_{4}-\mathrm{RBr}_{13}\right]=0.28 \mathrm{mM}$.

The fraction of pyrene that is more exposed to water can be determined using equation 5 : 


$$
\frac{I_{0}}{I_{0}-I}=\frac{1}{f K_{S V}[Q]}+\frac{1}{f}
$$

where $\mathrm{K}_{\mathrm{SV}}$ is the Stern-Volmer constant, $f$ is the fraction pyrene more accessible to water, and [Q] is the nitromethane concentration [37]. Plots of the results according to Eqn. 5 are linear for both polymers and the fraction $f$ was obtained from the intercept (Fig. 3).

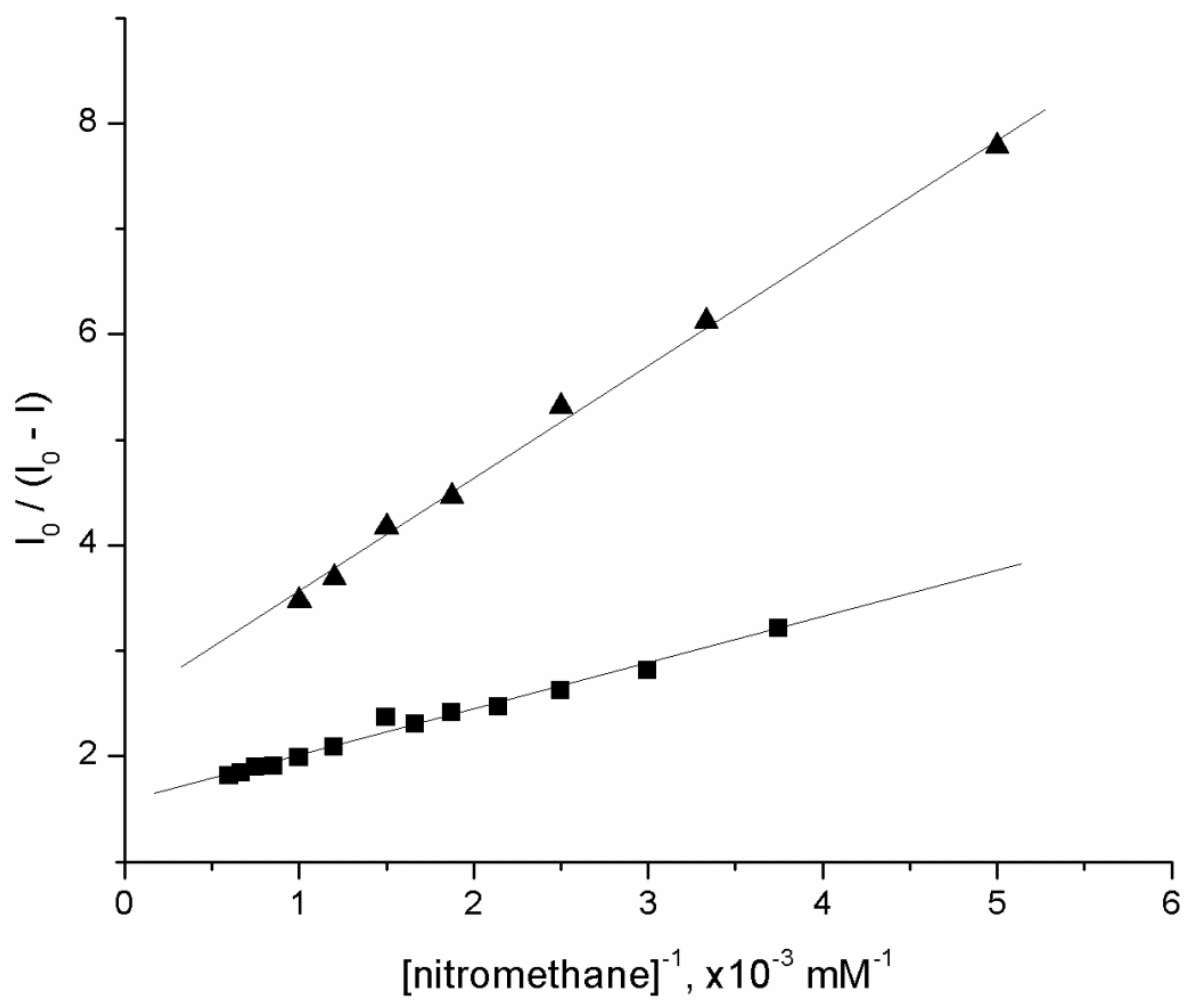

Figure 3. Modified Stern Volmer plot for quenching of pyrene fluorescence by nitromethane in $\mathrm{HPG}_{17}(\boldsymbol{\bullet})$, and $\mathrm{HPG}_{4}-\mathrm{RBr}_{13}(\boldsymbol{\Delta})$ micelles

The values of $f$ are 0.64 and 0.40 for $\mathrm{HPG}_{17}$ and $\mathrm{HPG}_{4}-\mathrm{RBr}_{13}$ aggregates, respectively. This means that most of the pyrene solubilized by aggregates formed by $\mathrm{HPG}_{17}$ is easily quenched by nitromethane, whereas in $\mathrm{HPG}_{4}-\mathrm{RBr}_{13}$ aggregates around $60 \%$ of the pyrene 
molecules are inaccessible to nitromethane. These results are consistent with the measured values of the ratio $I_{1} / I_{3}$, which suggest that the $H_{P G}$ aggregates are more accessible to water molecules. The lower accessibility of nitromethane to the $\mathrm{HPG}_{4}-\mathrm{RBr}_{13}$ aggregates may be attributed to a reduced flexibility of HPG chains due to the higher hydrophobic effect acting on the esterified chains.

The sizes and sizes distribution of aggregates were determined by DLS. The results shown in Fig. 4 indicate that at concentration below the $\mathrm{CAC}^{\mathrm{HPG}} 17$ form structures with hydrodynamic diameters of 3.5 and $22 \mathrm{~nm}$, whereas above the CAC the diameters change to 30 and $130 \mathrm{~nm}$. For $\mathrm{HPG}_{4}-\mathrm{RBr}_{13}$ two multimolecular aggregates with hydrodynamic diameters of 40 and $180 \mathrm{~nm}$ can be observed. Interestingly, in Fig. 5 it can be seen that the addition of p-alkylphenols to $\mathrm{HPG}_{17}$ aggregates induces changes in the size distribution, i.e. the distribution is shifted to slightly larger sizes and the smaller aggregates disappear. This result is completely opposite to the behavior reported for HPG- $\mathrm{C}_{18}$-PEG copolymers where solubilization of pyrene molecules induces a transition from multimolecular aggregates to unimolecular micelles [34]. On the other hand, for polymer micelles formed by linear block copolymers it has been found that solubilization of phenols and other additives induce micellar growth [38-40]. 


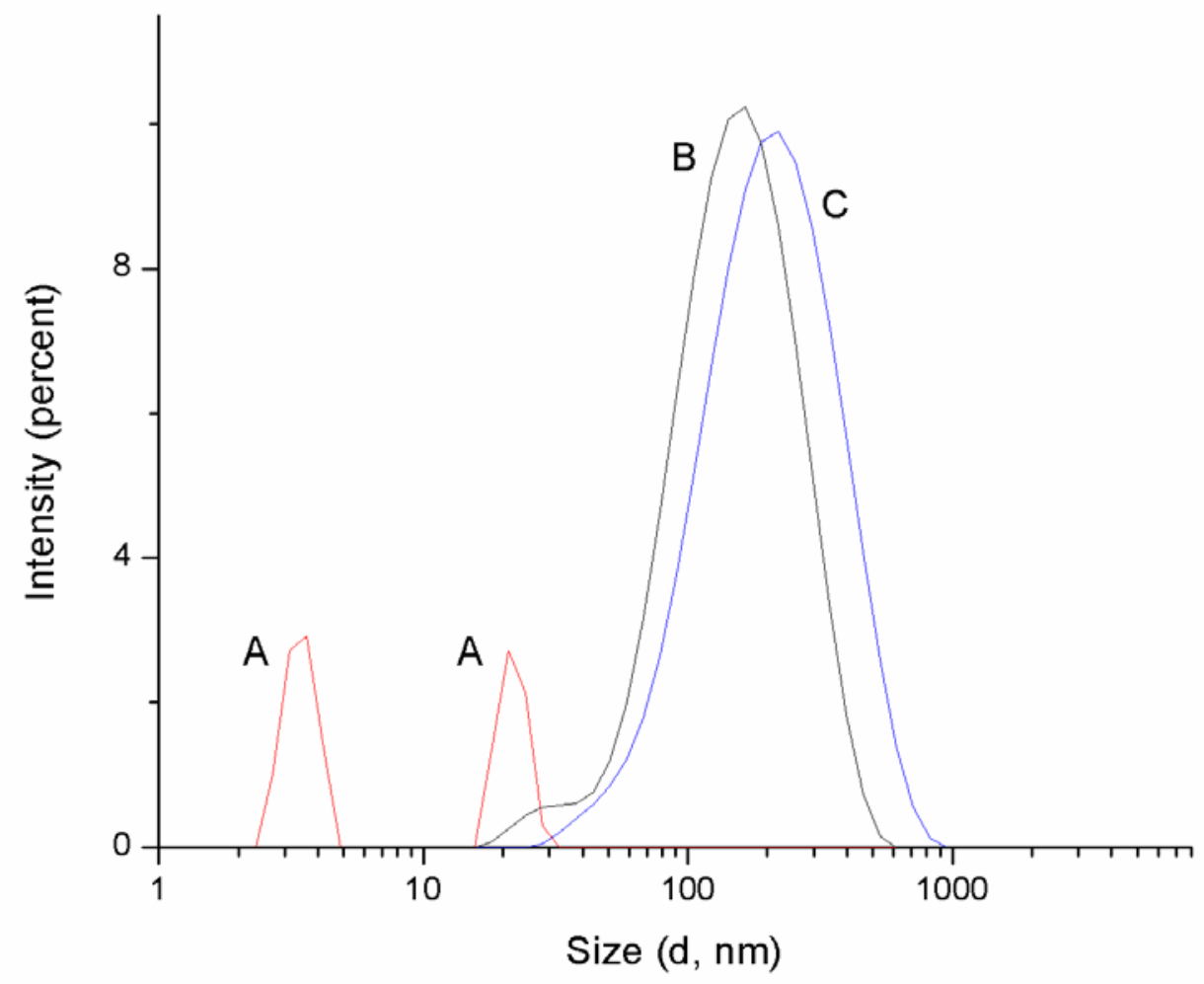

Figure 4. Hydrodynamic volumes of aggregates formed by: (A) $\mathrm{HPG}_{17}$ (0.7 mM); (B) $\mathrm{HPG}_{17}(10 \mathrm{mM})$; (C) $\mathrm{HPG}_{4}-\mathrm{RBr}_{13}(0.28 \mathrm{mM})$. DLS measurements were made at $25{ }^{\circ} \mathrm{C}$. 


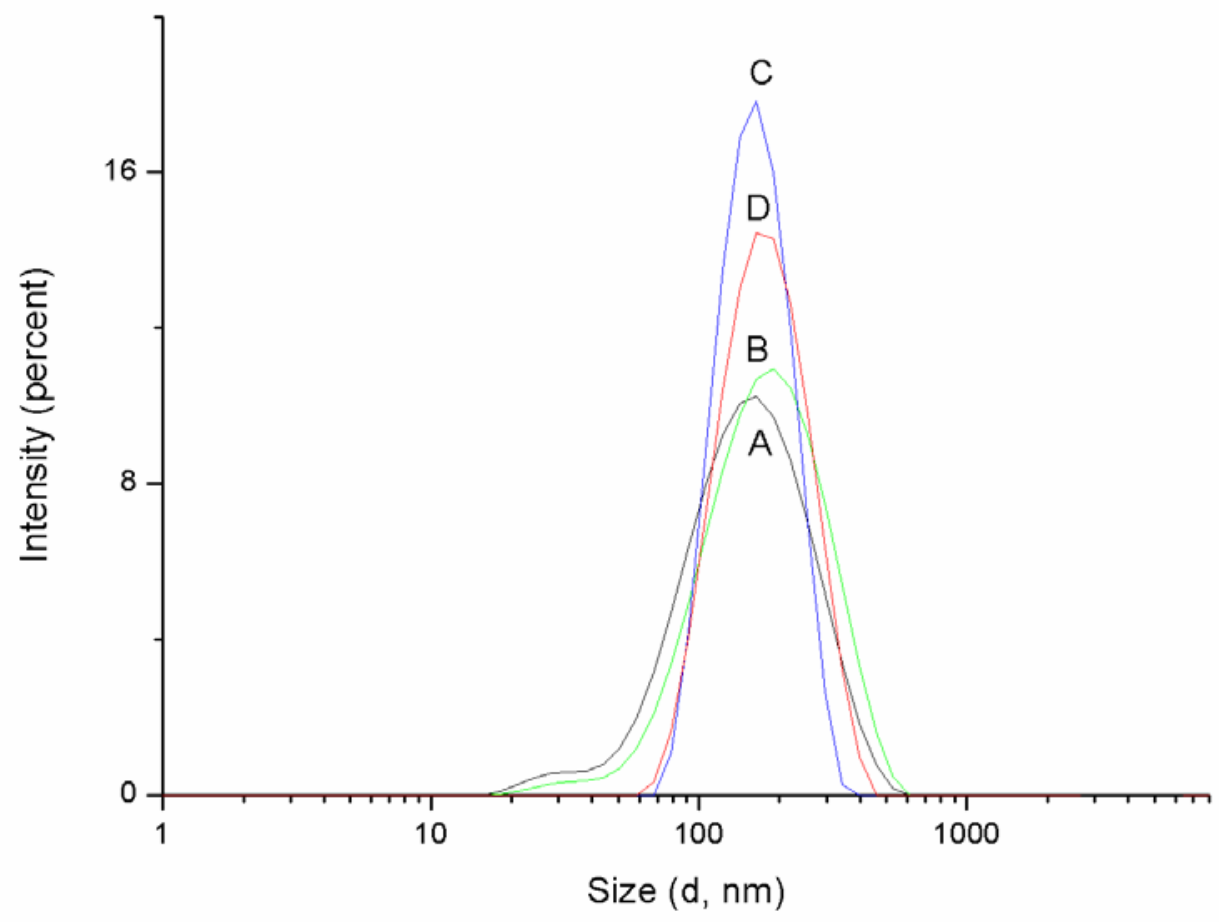

Figure 5. Hydrodynamic volumes of aggregates formed by $\mathrm{HPG}_{17}(10 \mathrm{mM})$ in absence (A) and presence of p-cresol (B), p-ethylphenol (C), p-butylphenol (D). DLS measurements were made at $25^{\circ} \mathrm{C}$. [Phenols] $=10 \mathrm{mM}$.

\subsection{Distribution of p-alkylphenols between aqueous phase and polymer aggregates}

The partition of phenols between the polymer and aqueous phase were determined for $\mathrm{HPG}_{17}$ and $\mathrm{HPG}_{4}-\mathrm{RBr}_{13}$ by using the pseudo-phase model. The distribution coefficients were obtained from the initial slope of the plots shown in Fig. 6 according to Eq. 2. 


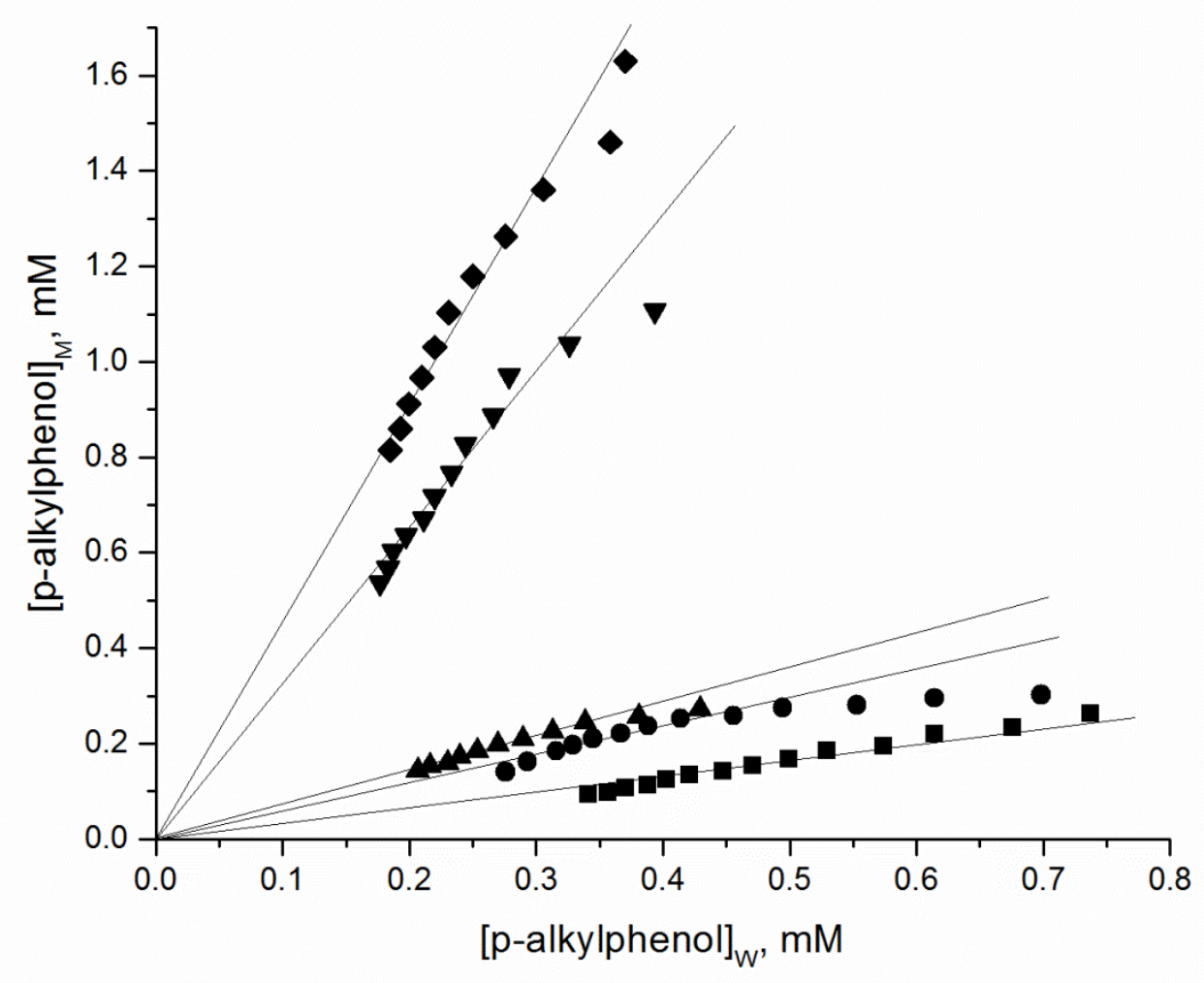

Figure 6. Measurements of distribution coefficients of p-alkylphenols between aqueous and polymer pseudo-phases, $\mathrm{K}_{\mathrm{S}}$ values are obtained from the initial slope. (ロ) p-ethyl phenol, $(\bullet)$ p-propyl phenol, ( $\mathbf{\nabla})$ p-butylphenol, at $\left[\mathrm{PG}_{17}\right]=10 \mathrm{mM}$; ( $\left.\mathbf{\Delta}\right)$ p-propylphenol, ( $)$ pbutylphenol at $\left[\mathrm{HPG}_{4}-\mathrm{RBr}_{13}\right]=0.28 \mathrm{mM}$

The partition coefficient in a mole fraction basis $K_{X}$ is related to $K_{S}$ through Eq. 4, and all calculated values are summarized in Table 2. The results show that the partition coefficients increases with increasing length of the side alkyl chain, and are larger for $\mathrm{HPG}_{4}-\mathrm{RBr}_{13}$ aggregates than for $\mathrm{HPG}_{17}$ aggregates. This behavior is in line with what has been reported for distribution of phenols in normal micelles, unimolecular and interpolymer micelles [2426,41]. 
Table 2. Partition coefficients and standard free energies of transfer of p-alkylphenols between aqueous phase and polymer phases

\begin{tabular}{|c|c|l|l|l|l|l|}
\hline & \multicolumn{3}{|c|}{$\mathrm{HPG}_{17}$} & \multicolumn{3}{c|}{$\mathrm{HPG}_{4}-\mathrm{RBr}_{13}$} \\
\hline p-Alkylphenol & $\mathrm{K}_{\mathrm{S}}$ & $\mathrm{K}_{\mathrm{X}}, \mathrm{x} 10^{4}$ & $\Delta \mu_{\mathrm{t}}^{0}, \mathrm{~kJ} \mathrm{~mol}^{-1}$ & $\mathrm{~K}_{\mathrm{S}}$ & $\mathrm{K}_{\mathrm{X}}, \mathrm{x} \mathrm{10^{4 }}$ & $\Delta \mu_{\mathrm{t}}^{0}, \mathrm{~kJ} \mathrm{~mol}^{-1}$ \\
\hline p-cresol & 60 & 0.3 & -19.97 & & & \\
\hline p-ethylphenol & 420 & 2.3 & -24.90 & 1160 & 6.4 & -27.40 \\
\hline p-propylphenol & 900 & 5.0 & -26.80 & 2610 & 14.5 & -27.45 \\
\hline p-butylphenol & 4865 & 27.0 & -31.00 & 16750 & 93.0 & -34.00 \\
\hline
\end{tabular}

The relationship between the partition coefficient $K_{X}$ and the standard free energy of transfer from the aqueous phase to the pseudo-micellar phase is given by

$$
\Delta \mu_{t}^{0}=\mu_{M}^{0}-\mu_{W}^{0}=-R T \ln K_{X}
$$

It has been shown that $\Delta \mu_{t}^{0}$ can be separated in additive contributions from different constituent groups of the transferred substrate [24,42]

$$
\Delta \mu_{t}^{0}=\Delta \mu_{A r}^{0}+n_{C} \Delta \mu_{C}^{0}
$$

where $\Delta \mu^{0}{ }_{A r}$ denotes the contribution of the parent aromatic group, $\Delta \mu_{C}^{0}$ is the incremental free energy per methylene group, and $n_{C}$ is the number of these groups attached to the parent group. Similar linear free energy relationships have been found in studies of partition of solutes between aqueous phase and organic solvents, micelles, and polymer micelles [24,25,42-44]. Plots of the values of $\Delta \mu_{t}^{0}$ against the number of carbon atoms in the alkyl group are almost linear for both polymer aggregates (Fig. 7). 


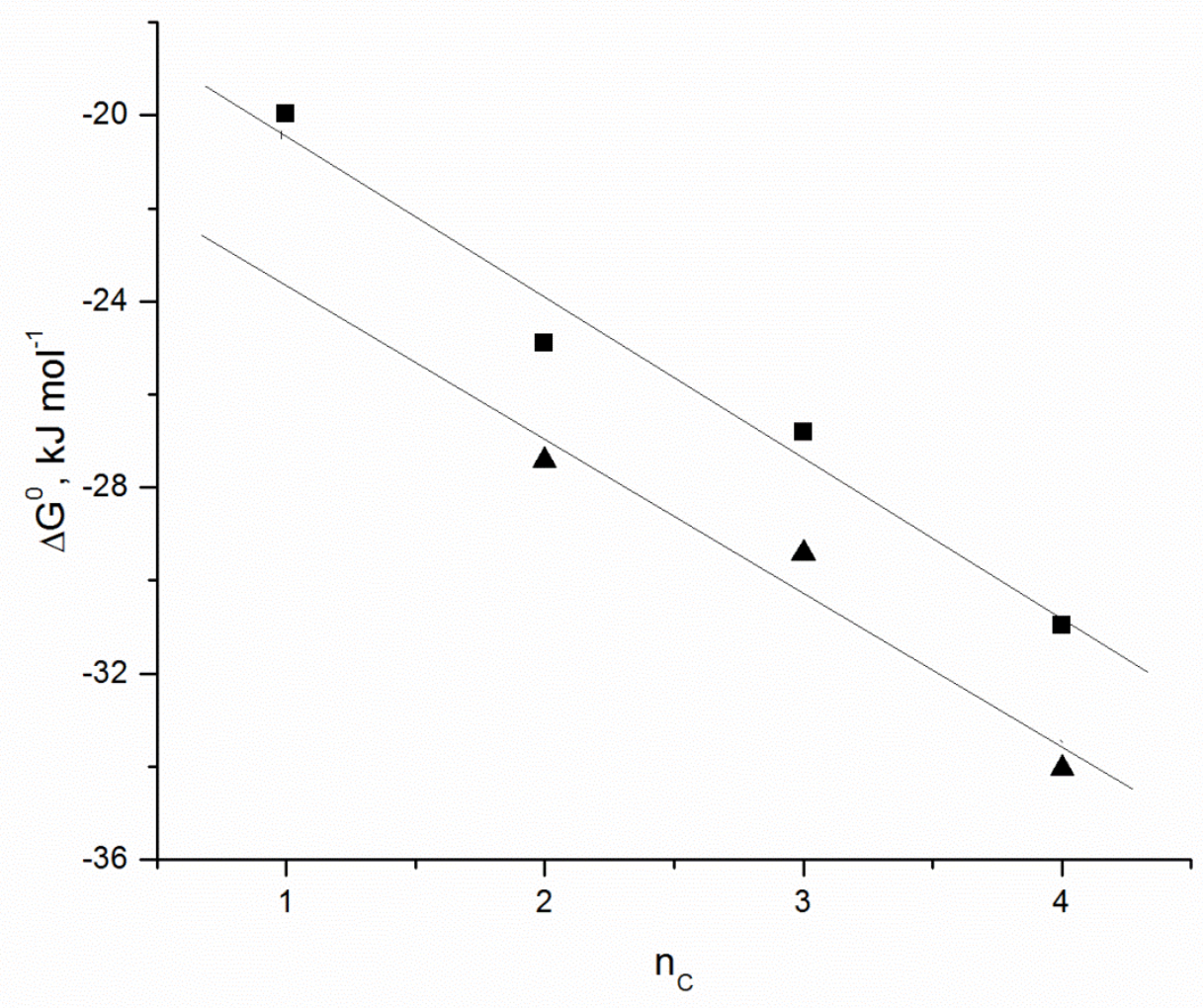

Figure 7. Standard free energy of transfer of p-alkyl phenols from water to polymer aggregates $\left(\Delta \mu_{t}^{0}\right)$, as a function of the number of carbon atoms on the alkyl chain. $\mathrm{HPG}_{17}$ (匹) and $\mathrm{HPG}_{4}-\mathrm{RBr}_{13}(\mathbf{\Delta})$.

The slopes are similar and the incremental free energy per methylene group, $\Delta \mu_{C}^{0}$, is -3.50 and $-3.30 \mathrm{~kJ} \mathrm{~mol}^{-1}$ for $\mathrm{HPG}_{17}$ and $\mathrm{HPG}_{4}-\mathrm{RBr}_{13}$, respectively, and agree well with that determined for transfer of methylene group from water to heptane $\left(-3.27 \mathrm{~kJ} \mathrm{~mol}^{-1}\right)$. These results suggest that alkyl chains have similar locations in both aggregates. On the other hand, the free energies of transfer of the phenol moiety from water into polymer aggregates, $\Delta \mu_{P h}^{0}$, obtained from the intercept are -16.9 and $-20.4 \mathrm{~kJ} \mathrm{~mol}^{-1}$ for $\mathrm{HPG}_{17}$ and $\mathrm{HPG}_{4^{-}}$ $\mathrm{RBr}_{13}$, respectively. The values of $\Delta \mu_{P h}^{0}$ are larger than those of $\Delta \mu_{C}^{0}$, which indicate that 
the location of p-alkylphenols in the aggregates formed by dendritic polymers is mainly determined by the transfer of the phenol moiety to the hydrophobic core. Interestingly, the

value of $\Delta \mu_{P h}^{0}$ measured for HPG is much lower than those measured in other polymer and SDS micelles [25,40]. This indicates that phenols in $\mathrm{PG}_{17}$ aggregates are located in a more polar environment than that provided by normal micelles. This conclusion is in line with fluorescence probing results indicating that water molecules enter freely into the $\mathrm{HPG}_{17}$ aggregate core.

\section{Conclusions}

A low molecular hyperbranched polyglycidol and its ester derivative were synthesized and characterized following standard procedures. The results indicate that a HPG with 17 units and a branching degree of 0.41 was obtained. The esterification of $\mathrm{HPG}_{17}$ gives $\mathrm{HPG}_{4}{ }^{-}$ $\mathrm{RBr}_{13}$, i.e. an ester with $78 \%$ of the hydroxyl groups converted into $\mathrm{RBr}$. These two HPG have different polarity and therefore it is expected that their aggregation behavior should be also different. The formation of multimolecular aggregates was monitored by fluorescence probing using pyrene as probe, and the measured CAC values are $2.5 \mathrm{mM}$ and $0.25 \mathrm{mM}$ for $\mathrm{HPG}_{17}$ and $\mathrm{HPG}_{4}-\mathrm{RBr}_{13}$, respectively. The size and size distribution of the formed aggregates were determined by DLS. At low concentrations of HPG aggregates of $3.5 \mathrm{~nm}$ and $22 \mathrm{~nm}$ were observed, whereas at concentrations above the CAC larger aggregates are observed for both HPG. In the whole range of concentrations these aggregates are able to solubilize pyrene. Above the CAC the solubilization of p-alkylphenols shifts the size distribution to larger sizes and induces the disappearance of the smaller aggregates. The partition coefficients of p-alkylphenols and the standard free energy of transfer from the aqueous phase to the pseudo-micellar phase were determined for both polymers at concentrations well above the CAC. The results show that $\mathrm{K}_{\mathrm{X}}$ increases with increasing 
length of the side alkyl chain, and are larger for $\mathrm{HPG}_{4}-\mathrm{RBr}_{13}$ micelles than for $\mathrm{HPG}_{17}$

micelles. The free energy values are negative and can be separated in contributions from the phenol constitutive groups. The location into the aggregate and amount of transfer is determined mainly by the phenolic ring.

\section{Acknowledgements}

This work was supported by FONDECYT Grant 1130742

\section{References}

[1] A. Sunder, R. Hanselmann, H. Frey, R. Mulhaupt, Controlled synthesis of hyperbranched polyglycerols by ring-opening multibranching polymerization, Macromolecules 32 (1999) 4240-4246.

[2] A. Sunder, R. Mulhaupt, R. Haag, H. Frey, Hyperbranched polyether polyols: A modular approach to complex polymer architectures, Adv.Mater. 12 (2000) 235239.

[3] C. Gao D. Yan, Hyperbranched polymers: from synthesis to applications, Prog.Poly.Sci. 29 (2004) 183-275.

[4] D. Y. Yan, C. Gao, H. Frey, Hyperbranched Polymers, John Wiley, Hoboken, NJ, 2011.

[5] X.Y. Zhu, Y.F. Zhou, D.Y. Yan, Influence of Branching Architecture on Polymer Properties, J.Polym.Sci.Part B: Polym.Phys. 49 (2011) 1277-1286.

[6] I.N. Kurniasih, J. Keilitz, R. Haag, Dendritic nanocarriers based on hyperbranched polymers, Chem.Soc.Rev 44 (2015) 4145-4164.

[7] L. Mou, N. Chen, K. Zhu, Y. Chen, X. Luo, Copolymer of star poly(epsiloncaprolactone) and polyglycidols as potential carriers for hydrophobic drugs, Polym.Adv.Technol. 23 (2012) 748-755.

[8] Q. Zhu, F. Qiu, B. Zhu, X. Zhu, Hyperbranched polymers for bioimaging, RSC Advances 3 (2013) 2071-2083.

[9] D. Wang, T. Zhao, X. Zhu, D. Yan, W. Wang, Bioapplications of hyperbranched polymers, Chem.Soc.Rev 44 (2015) 4023-4071. 
[10] Y. Zheng, S. Li, Z. Weng, C. Gao, Hyperbranched polymers: advances from synthesis to applications, Chem.Soc.Rev 44 (2015) 4091-4130.

[11] H. Hong, Y. Mai, Y. Zhou, D. Yan, Y. Chen, Synthesis and supramolecular selfassembly of thermosensitive amphiphilic star copolymers based on a hyperbranched polyether core, J.Polym.Sci.Part A: Polym.Chem. 46 (2008) 668-681.

[12] Y.F. Zhou D.Y. Yan, Supramolecular self-assembly of amphiphilic hyperbranched polymers at all scales and dimensions: progress, characteristics and perspectives, Chem.Comm. 00 (2009) 1172-1188.

[13] Z.F. Jia, Y.F. Zhou, D.Y. Yan, Amphiphilic star-block copolymers based on a hyperbranched core: Synthesis and supramolecular self-assembly, J.Polym.Sci.Part A: Polym.Chem. 43 (2005) 6534-6544.

[14] B.N.S. Thota, L.H. Urner, R. Haag, Supramolecular Architectures of Dendritic Amphiphiles in Water, Chem.Rev. 116 (2016) 2079-2102.

[15] Y. Zhou, W. Huang, J. Liu, X. Zhu, D. Yan, Self-Assembly of Hyperbranched Polymers and Its Biomedical Applications, Adv.Mater. 22 (2010) 4567-4590.

[16] H. Jin, W. Huang, X. Zhu, Y. Zhou, D. Yan, Biocompatible or biodegradable hyperbranched polymers: from self-assembly to cytomimetic applications, Chem.Soc.Rev 41 (2012) 5986-5997.

[17] F. Du, S. Honzke, F. Neumann, J. Keilitz, W. Chen, N. Ma, S. Hedtrich, R. Haag, Development of biodegradable hyperbranched core-multishell nanocarriers for efficient topical drug delivery, J.Control.Release 242 (2016) 42-49.

[18] H. Hong, Y. Mai, Y. Zhou, D. Yan, J. Cui, Self-assembly of large multimolecular micelles from hyperbranched star copolymers, Macrom.Rap.Comm. 28 (2007) 591596.

[19] M.R. Radowski, A. Shukla, H. von Berlepsch, C. Bottcher, G. Pickaert, H. Rehage, R. Haag, Supramolecular aggregates of dendritic multishell architectures as universal nanocarriers, Angew.Chem.Int.Ed. 46 (2007) 1265-1269.

[20] H.X. Cheng, S.G. Wang, J.T. Yang, Y.F. Zhou, D.Y. Yan, Synthesis and selfassembly of amphiphilic hyperbranched polyglycerols modified with palmitoyl chloride, J.Colloid Interf.Sci. 337 (2009) 278-284.

[21] X.Y. Sun, Y.F. Zhou, D.Y. Yan, Rendering Hyperbranched Polyglycerol Adjustably Thermoresponsive by Adamantyl Modification and Host/Guest Interaction, Macromol.Chem.Phys. 211 (2010) 1940-1946.

[22] I.N. Kurniasih, H. Liang, J.P. Rabe, R. Haag, Supramolecular Aggregates of Water Soluble Dendritic Polyglycerol Architectures for the Solubilization of Hydrophobic Compounds, Macrom.Rap.Comm. 31 (2010) 1516-1520. 
[23] S. Stefani, S.K. Sharma, R. Haag, P. Servin, Core-shell nanocarriers based on PEGylated hydrophobic hyperbranched polyesters, Eur.Polym.J. 80 (2016) 158168.

[24] L. Sepulveda, E.A. Lissi, F. Quina, Interactions of neutral molecules with ionic micelles, Adv.Colloid Interf.Sci. 25 (1986) 1-27.

[25] A.F. Olea, R.G. Barraza, I. Fuentes, B. Acevedo, F. Martinez, Solubilization of phenols by intramolecular micelles formed by copolymers of maleic acid and olefins, Macromolecules 35 (2002) 1049-1053.

[26] A.F. Olea C. Gamboa, Solubilization of phenols in surfactant/polyelectrolyte systems, J.Colloid Interf.Sci. 268 (2003) 63-67.

[27] A. Sunder, T. Bauer, R. Mulhaupt, H. Frey, Synthesis and thermal behavior of esterified aliphatic hyperbranched polyether polyols, Macromolecules 33 (2000) 1330-1337.

[28] S. Maier, A. Sunder, H. Frey, R. Mulhaupt, Synthesis of poly(glycerol)-blockpoly(methyl acrylate) multi-arm star polymers, Macrom.Rap.Comm. 21 (2000) 226230.

[29] K. Kalyanasundaram J.K. Thomas, Environmental effects on vibronic band intensities in pyrene monomer fluorescence and their application in studies of micellar systems, J.Am.Chem.Soc. 99 (1977) 2039-2044.

[30] A.F. Olea J.K. Thomas, Fluorescence Studies of the Conformational Changes of Poly(methacrylic acid) with pH, Macromolecules 22 (1989) 1165-1169.

[31] D.C. Dong M.A. Winnik, The Py scale of solvent polarities. Solvent effects on the vibronic fine structure of pyrene fluorescence and empirical correlations with ET and Y values, Photochem.Photobiol. 35 (1982) 17-21.

[32] W. Binana-Limbele R. Zana, Fluorescence Probing of Microdomains. 1. Use of Pyrene to Study the Conformational State of Polysoaps and their Comicellization with Cationic Surfactants, Macromolecules 20 (1987) 1331-1335.

[33] M.R. Radowski, A. Shukla, H. von Berlepsch, C. Bottcher, G. Pickaert, H. Rehage, R. Haag, Supramolecular aggregates of dendritic multishell architectures as universal nanocarriers, Angew.Chem.Int.Ed. 46 (2007) 1265-1269.

[34] R.K. Kainthan, C. Mugabe, H.M. Burt, D.E. Brooks, Unimolecular micelles based on hydrophobically derivatized hyperbranched polyglycerols: Ligand binding properties, Biomacromolecules 9 (2008) 886-895.

[35] Y. Teng, M.E. Morrison, P. Munk, S.E. Webber, K. Prochazka, Release kinetics studies of aromatic molecules into water from block polymer micelles, Macromolecules 31 (1998) 3578-3587. 
[36] A.F. Olea, P. Silva, I. Fuentes, F. Martinez, D. Worrall, Probing solubilization sites in block copolymer micelles using fluorescence quenching, J.Photochem.Photobiol.A: Chem. 217 (2011) 49-54.

[37] Lakowicz J.R., Principles of Fluorescence Spectroscopy, Plenum Press, New York, 1999.

[38] J. Dey, S. Kumar, S. Nath, R. Ganguly, V. Aswal, K. Ismail, Additive induced core and corona specific dehydration and ensuing growth and interaction of Pluronic F127 micelles, J.Colloid Interf.Sci. 415 (2014) 95-102.

[39] R. Ganguly, K. Kuperkar, P. Parekh, V. Aswal, P. Bahadur, Phenol solubilization in aqueous Pluronic $(\mathrm{R})$ solutions: Investigating the micellar growth and interaction as a function of Pluronic (R) composition, J.Colloid Interf.Sci. 378 (2012) 118-124.

[40] A.F. Olea, H. Carrasco, L. Espinoza, B. Acevedo, Solubilization of p-alkylphenols in Pluronics F-68 and F-127 micelles: Partition coefficients and effect of solute on the aggregate structure, J.Chil.Chem.Soc. 59 (2014) 2451-2454.

[41] R.G. Barraza, A.F. Olea, C.E. Valdebenito, V. Dougnac, I. Fuentes, Solubilization of p-nitrophenol in aggregates formed by hydrophobically modified polyelectrolytes, J.Colloid Interf.Sci. 275 (2004) 434-438.

[42] C. Tanford, The Hydrophobic Effect, 2nd, John Wiley, New York, 1988.

[43] C. Gamboa, A.F. Olea, H.E. Rios, M. Henriquez, Association of Alcohol with Cationic Micelles, Langmuir 8 (1992) 23-26.

[44] C.H. Salamanca, R.G. Barraza, B. Acevedo, A.F. Olea, Hydrophobically modified polyelectrolytes as potential drugs reservoirs of n-alkyl-nitroimidazoles , J.Chil.Chem.Soc. 52 (2007) 1025-1029. 